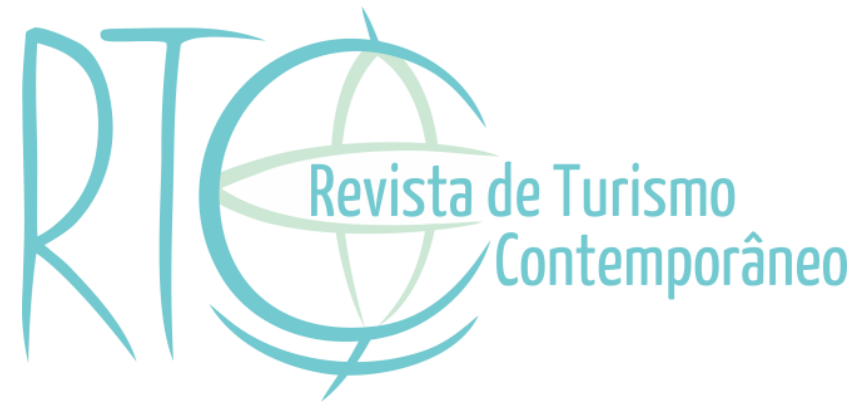

\title{
As possibilidades de implementação do turismo cinematográfico em Belém do Pará
}

The possibilities of an implementation of the cinematographic tourism in Belém do Pará

\section{Marcos André de Menezes Costa}

Especialista em Planejamento e Gestão do Turismo e do Lazer pelo Núcleo de Altos Estudos Amazônicos -NAEA da Universidade Federal do Pará -UFPA, Belém/PA, Brasil E-mail: marcosandrecosta@yahoo.com.br 


\begin{abstract}
RESUMO
O artigo mostra a união do turismo com o cinema, um novo segmento do turismo mundial. São apontadas considerações básicas, a relação com uma film commission e como a cidade de Brasília tornou-se referência nesse segmento no Brasil. Metodologicamente, adota-se a pesquisa bibliográfica, exploratória, qualitativa e indutiva, procurando trabalhar de forma mais natural possível para sistematização das ideias. O objetivo da pesquisa é analisar como o turismo cinematográfico pode ser implementado em Belém do Pará. Os resultados iniciais mostram amplas possibilidades para tal implementação, pois a cidade possui diferenciados atrativos naturais, patrimoniais, culturais e potenciais turísticos para atrair turistas.
\end{abstract}

Palavras-chave: Turismo. Cinema. Turismo Cinematográfico. Implementação.

\title{
ABSTRACT
}

The article shows the union between tourism and cinema, a new segment of world tourism. Basic considerations are pointed, the relationship with a film commission and as the city of Brasília became reference in film tourism in Brazil. Methodologically, adopts the bibliographic research, exploratory, qualitative and inductive, looking to work the most natural way possible for the systematization of ideas. The objective of the research is to analyze how the film tourism can be implemented in Belém of Pará. The initial results show great possibilities for implementation, because the city has different natural attractions, heritage, cultural and touristic potential to attract tourists.

Keywords: Tourism. Cinema. Film Tourism. Implementation. 


\section{INTRODUÇÃO}

A atividade turística ultimamente está em contínuo crescimento, pois não é somente direcionado a viagem e lazer, mas mercadológica com investimentos governamentais e empreendimentos privados, tonando-se também um elemento social e cultural em constante desenvolvimento. A necessidade humana de descobrir novas experiências e diferentes culturas se expande de forma em que o comércio turístico, vê-se obrigado a (re)criar novos atrativos para seus diversos consumidores. Concordando com Azevedo, Figueiredo, Nóbrega e Maranhão (2013, p. 11):

O turismo tem sido um dos aspectos mais marcantes da sociedade atual. Os deslocamentos para lazer, as viagens de férias, o entretenimento associado à viagem, tem feito milhares de pessoas se movimentarem no mundo, principalmente pela existência de meios de transportes rápidos, fáceis e com uma rede que conecta quase sem restrições a maior parte do mundo organizado pelo capital. Isso transforma o fato turístico, observável, em fenômeno, especial.

O tema escolhido, turismo cinematográfico, surgiu a partir de variadas questões observadas em Belém do Pará como o patrimônio histórico e cultural, a gastronomia, a religiosidade, as variadas manifestações artísticas e porque a mesma ainda não tem essa menção nesse direcionamento como a cidade de Brasília que é referência em turismo cinematográfico, e de acordo com o Ministério do Turismo [MTur], (Brasil, 2010, p. 18), "[...] em Brasília já foram filmados cerca de 200 filmes, que fizeram uso de seus cenários naturais e urbanos como locação. E em pelo menos um quarto desses filmes, a própria cidade foi personagem ou mesmo protagonista da trama". O segmento turismo cinematográfico destacase mundialmente com o objetivo de promover, divulgar e permitir visibilidade da imagem de uma cidade por meio de um filme, de uma novela, de um documentário, de uma publicidade, etc., possibilitando atrair visitantes a partir do que se vê nos meios de comunicação.

Logo, diante desse referenciamento, utilizou-se inicialmente a cartilha do turismo cinematográfico elaborada pelo MTur em parceria com o Instituto Dharma feita para ampliação do assunto no Brasil com a finalidade de direcionamento e a possibilidade de implementação em uma localidade. Então, é possível uma reflexão diante do seguinte questionamento: Com a possibilidade da implementação do turismo cinematográfico, como os cenários turísticos de Belém do Pará possam ser aproveitados em uma obra cinematográfica com foco na divulgação, atraindo cada vez mais visitantes para a capital paraense?

A partir desta questão, este artigo direcionou identificar o turismo cinematográfico e 
como todos os seus desdobramentos podem colaborar para fortalecer, divulgar e fomentar cada vez mais o turismo na região, além da importância da exposição da paisagem turística amazônica. E por fim, valorizar a inter-relação do turismo com o cinema fazendo uma aliança mais contemporânea com a imagem turística e verificando o potencial da cidade para tal desenvolvimento. Portanto, perante o questionamento da problemática, torna-se proeminente o estudo do tema diante das possibilidades de contribuições para noticiar os cenários turísticos de Belém e seu entorno. O turismo cinematográfico tem auxiliado a fortalecer e fomentar o trade turístico em uma cidade, atraindo turistas específicos ou não no Brasil e no mundo.

\section{A UNIÃO DO TURISMO COM O CINEMA}

Para um entendimento mais completo a partir deste assunto, é preciso entender o que direciona o turismo. De acordo Endres (2015, p. 288):

O turismo é hoje uma das principais atividades para estimular o desenvolvimento local em qualquer região do Brasil. Afinal, o turismo é uma atividade econômica e, como tal, as possibilidades de geração de emprego e renda predominam em seu discurso. Além do mais, seus efeitos e repercussões ambientais e sociais, diferentemente de outras atividades econômicas, o colocam como uma atividade que possibilita uma maior atenção na conservação ambiental e, principalmente, como fator de inclusão social pela diversidade de sua cadeia produtiva.

Verifica-se que o turismo proporciona diversas alternativas, além de mercadológico, também é lazer, viagens e com um segmento social presente na vida empírica com muitas interatividades para desbravar novas e inúmeras experiências em culturas diferenciadas. Segundo o Art. $2^{\circ}$ da Lei $n^{\circ} 11.771$, de 11 de setembro de 2008, “[...] considera-se turismo as atividades realizadas por pessoas físicas durante viagens e estadas em lugares diferentes do seu entorno habitual, por um período inferior a um ano, com finalidade de lazer, negócios ou outras” (Brasil, 2008, p. 01). Nessa perspectiva, entende-se que além da procura por novos conhecimentos e descobertas na realização de uma viagem, pode-se combinar com outros temas como o cinema, que é muito variável e compreendido em inúmeros direcionamentos como será verificado a seguir.

Atribui-se ao cinema, de acordo com o MTur, “[...] indústria multibilionária que gera hoje uma imensa circulação de pessoas ao redor do mundo, movimentando mercados de produção, distribuição, direitos autorais, tecnologia, etc. [...]” (Brasil, 2007, p. 06). Nota-se que o cinema sempre será um entretenimento bastante presente na vida do ser humano, além 
de ser uma potência mundial da comunicação, para Melo (2009, p. 25), "O cinema, maior veículo de suporte de difusão da imagem em movimento [...]”. É também do divertimento, é histórico, é inovador, tem o poder de fascinação e tem tradição cultural, e conforme Schneider (2012, p. 11), “[...] possui a característica de fascinar e envolver as pessoas, de transportá-las para outro mundo, para outra realidade, de fazer com que vejam e sintam pessoalmente àquilo que ainda não conheciam, ou que já haviam visto através de fotos, vídeos ou de um filme".

Geralmente, o cinema tem sempre algo a contribuir, pois tem uma força de midiatização impressionante. Atualmente, a mídia em si está muito presente no cotidiano, influenciando, alterando e gerando reflexões no que se tem visto e de como se interpreta o que se está vendo. De acordo com Rosa (2014, pp. 239-240), "[...] vive-se hoje um cenário de midiatização, ou seja, a relação entre os processos sociais e comunicacionais que resultam na produção de sentido e, portanto, na comunicação, é atravessada por lógicas da mídia o que altera o modo de organizar a vida social." Nesse sentido, esse meio midiático possui muita ficção ou verdadeiras lições, e mesmo a história sendo verídica, sensivelmente é modificada, e muitas vezes as verdades que são filmadas ficam absolutas com meras coincidências, mas na sua maioria, uma verdadeira fantasia.

Com tanta variedade e amplitude dos estudos relacionados do turismo com o cinema, tornou-se imprescindível observar exemplos e as singularidades, pois devido a essa grande tendência mundial, uma das cidades mais beneficiadas nessa aliança é o Rio de Janeiro.

A cidade do Rio de Janeiro talvez seja o destino brasileiro que mais se beneficia com a promoção de imagens veiculadas mundialmente, através de produções audiovisuais. Como exemplo, pode ser citado o significativo interesse de turistas nacionais e internacionais por assistir jogos de futebol no Maracanã, passear pelo bairro da Lapa integrando história, música, dança e gastronomia, pacotes turísticos que contemplam tour pelos 14 galpões que compõem a Cidade do Samba, quartel-general de toda a produção do carnaval carioca, transmitido por imagens a todos os continentes, sem contar a tradicional caminhada pelo calçadão de Copacabana, a praia mais famosa do mundo (Melo, 2009, p. 66).

Sem dúvida, observa-se que a cidade do Rio de Janeiro é diferenciada, além dos inúmeros eventos como os Jogos Olímpicos em 2016, há muitos e variados cenários turísticos, tanto na capital como no interior, que contemplam essa localidade com a chegada de novos turistas constantemente, multiplicando e fortalecendo o trade turístico.

Contudo, o que se vê? Como se interpreta o que se vê? Qual é a grande sensibilidade do olhar do cinema com essa relação mais turística? 
A relação entre turismo e cinema pode assumir diversas formas: a produção de documentários para divulgação de destinos turísticos; a criação de produtos turísticos a partir de estúdios de cinema; o turismo de negócios associado aos festivais de cinema; e finalmente, a deslocação a um lugar porque este está relacionado com um determinado filme, [...], e pela importância que as imagens de um filme podem ter a construção da ideia de um dado território, mas também pelos efeitos sentidos no território, pela procura deste por parte dos turistas. [...]. O turismo e o cinema são analisados sob várias perspectivas que visam caracterizar as diferentes especialidades que esta relação tem, nomeadamente, a difusão e consolidação do turismo cinematográfico como forma de turismo cultural, [...] e, finalmente, o papel das autoridades locais como elemento potencializador do turismo cinematográfico (Almeida, Fumega \& Alves, 2009, p. 01).

Analisa-se que a responsabilidade do audiovisual em parceria com o turismo, seja no conceito, nas interpretações ou nas práticas da divulgação das imagens é essencial, desde que seja bem aproveitado, trabalhado, direcionado, planejado, etc. Portanto, essa aliança entre o turismo e o cinema em Belém do Pará ou em qualquer lugar que for implementado, possivelmente possibilitará (re)descobrir não só os cenários turísticos, mas também a cultura, a arte, as paisagens ambientais e sociais, e permitindo assim, resultados relevantes entre os novos visitantes e os visitados na região e seu entorno.

\section{METODOLOGIA}

Realizou-se através de pesquisa bibliográfica, exploratória, indutiva e qualitativa. Primeiramente, procedeu-se um levantamento completo bibliograficamente em livros, artigos, monografias, entre outros para sistematização das informações.

A pesquisa bibliográfica visa oferecer diretrizes para a elaboração de trabalhos acadêmicos e é desenvolvida com base em material já elaborado: livros, artigos de periódicos científicos e, atualmente, materiais disponibilizados pela internet. Por meio da pesquisa bibliográfica, é possível encontrar o documento que melhor se adapte ao tema que você busca (Rover, 2006, p. 97).

Com esse esclarecimento, direcionaram-se os procedimentos para alcançar os objetivos que ofereceu uma amplitude generalizada do que já foi expandido sobre o tema no Brasil, e ajudou consideravelmente, no desenvolvimento e enriquecimento do conteúdo.

Para tornar a investigação mais completa, utilizou-se a pesquisa exploratória, indutiva e qualitativa para que fosse desenvolvido o tema com a maior naturalidade possível, observando a verdade, sem muitas alterações. 
Na pesquisa exploratória, o objetivo é obter maior familiaridade com o problema para torná-lo explícito ou a construir hipóteses. Assumindo a forma de pesquisa bibliográfica ou estudo de caso, pode conter entrevistas, questionários, análise de exemplos, etc. (Siena, 2007, p. 64).

Método Indutivo - proposto por Bacon: O método proposto por Bacon baseia-se na observação sistemática e a experiência dos fenômenos e fatos naturais: Cabe à experiência confirmar a verdade; A abstração pósobservação não oferece um conhecimento completo do fenômeno; $\mathrm{O}$ método tenta impedir a formulação de generalizações que extrapolem os limites de validade dos resultados alcançados em determinado experimento. (Jung, 2003, p. 84).

$\mathrm{Na}$ pesquisa qualitativa o pesquisador procura reduzir a distância entre a teoria e os dados, entre o contexto e ação, usando a lógica da análise fenomenológica, isto é, da compreensão dos fenômenos pela sua descrição e interpretação. As experiências pessoais do pesquisador são elementos importantes na análise e compreensão dos fenômenos estudados. A pesquisa qualitativa tem as seguintes características (Teixeira, 2006, p. 137)

Com essas observações, buscou-se atingir todos os objetivos. Cientificamente, o turismo cinematográfico é um assunto ainda pouco estudado, pois há deficiência em encontrar materiais específicos para dar suporte ao tema. Analisou-se criteriosamente o que já foi pesquisado, na tentativa de fazer uma relação mais singular com a imagem, com a natureza e com a identidade do turismo e do cinema em Belém do Pará.

Posteriormente, realizou-se uma pesquisa de campo, com a finalidade de descobrir as particularidades do local. A pesquisa de campo,

visa ao estudo e à investigação de um problema relativo a determinado segmento social. Para empreender tal pesquisa, coletam-se - por meio de questionários e/ou de entrevistas - dados referentes ao segmento social alvo da pesquisa - com o objetivo de formular conclusões sobre ele (Didio, 2014, pp. 23-24).

Compreende-se que o estudo de caso direciona uma melhor amplitude para que sejam alcançados e analisados os objetivos da pesquisa. Nesse contexto, serviu para verificar as opiniões dos atores envolvidos e os cenários turísticos que possam servir de pano de fundo para uma obra cinematográfica. 


\section{TURISMO CINEMATOGRÁFICO}

Nesta seção tem-se inicialmente como referência a Cartilha do Turismo Cinematográfico Brasileiro e o Estudo de Sinergia e Desenvolvimento entre as Indústrias do Turismo \& Audiovisual, idealizado pelo Ministério do Turismo ambas em 2007. A partir desses estudos, verifica-se que a relação do turismo com o cinema tem motivado a visita de turistas específicos ou não em uma região mostrada tanto no cinema, na TV ou na internet, como também:

[...] pelo movimento dos turistas em dois sentidos: o de conhecer as estruturas que abrigam as produções cinematográficas e os mecanismos que dão forma a este mundo de fantasia por meio de visitas aos estúdios e sets de filmagem; e o de conhecer os destinos e cenários (locações) onde a narrativa do filme se sucedeu, na tentativa de viver momentos e emoções criadas no filme e introjetadas no imaginário do espectador-turista (Albernaz, 2009, p. 17).

O desejo de conhecer um destino que foi cenário cinematográfico é uma atividade moderna e diferenciada que induz os set-jetters ${ }^{1}$ ou não no Brasil e no mundo a visitar uma região onde determinada produção cinematográfica foi designada na expectativa de atrair novos turistas para apreciar e vivenciar as particularidades in loco. Concordando com Barradas (2013, p. 01), "Cerca de 40 milhões de turistas escolhem o seu destino de férias baseados nas regiões em que os seus filmes de eleição foram gravados, impulsionando o turismo destes países".

Esse segmento do turismo vem se consolidando e se constituindo como uma atividade altamente única. Para Schneider (2012, p. 14), “[...] vem sendo cada vez mais utilizado no cinema mundial e nacional como recurso para atrair turistas às regiões que serviram de locação nas filmagens de produções cinematográficas, audiovisuais e televisivas". Por onde foi ou está sendo implantado, o turismo cinematográfico torna-se diferenciado, pois valoriza a localidade dando visibilidade para cenários até esquecidos da comunidade e atraindo cada vez mais visitantes com a divulgação. Conforme o MTur, (Brasil, 2007, p. 05), “[...] três fatores estimulam os turistas cinematográficos: o lugar (cenários e paisagens), as personalidades (a estrela do filme ou o personagem) e as características artísticas (o gênero do roteiro)”.

A seguir na figura 01 , será mostrado uma tabela ${ }^{2}$ que foi criada para mostrar os

\footnotetext{
${ }_{2}^{1}$ Set-Jetters são turistas que viajam para as paisagens que servem de pano de fundo de filmes (Brasil, 2007, p. 03).

2 Segundo o MTur, (Brasil, 2007, p. 11), essa tabela foi extraída do estudo "Promoting Destinations via film Tourism: an empirical identification of supporting marketing initiatives de S. Hudson e J. R. B. Ritchie”. Fonte: Rilley and Van Doren
} 
possíveis impactos do turismo cinematográfico sendo implementado em uma cidade, ou seja, apresenta exatamente o que uma locação recebeu de visitantes e o lucro com a realização de um filme. A partir desses exemplos, é possível avaliar o que a capital paraense ou uma região poderá receber, em longo prazo, com a concretização de uma obra cinematográfica. É verificado na lista: os filmes, as locações, os números de visitantes ou faturamento.

Figura 01 - Impactos do turismo cinematográfico.

\section{IMPACTOS DO TURISMO CINEMATOGRÁFICO}

\begin{tabular}{|c|c|c|}
\hline FLME OU SÉRIE DE TV & LOCAÇÃO & $\begin{array}{l}\text { IMPACTO EM NUMMERO DE } \\
\text { VISIMATIES OU FATURAMENT }\end{array}$ \\
\hline Coraçāo Valente & Wallace Manument, Escócia & $\begin{array}{l}300 \% \text { de aumento do námera de } \\
\text { visitantes depois do lançarnento }\end{array}$ \\
\hline Heartbeat $(-\mid)$ & Goathland, North Yarkshire, Escócia & $\begin{array}{l}3 \text { veres o numero médio de visitantes } \\
\text { no ano seguinte }\end{array}$ \\
\hline Amargo Pesadelo & $\begin{array}{l}\text { Payburn County, Georgia, Estados } \\
\text { Unidos }\end{array}$ & $\begin{array}{l}20 \text { mil turistas adicionais an ano cam } \\
\text { receitas de } 2 \text { a } 3 \text { milhūes de dólares }\end{array}$ \\
\hline Dança com Lobos & Fort Hayes, Kansas, Estadas Unidas & $\begin{array}{l}25 \% \text { de aumento comparado coem } \\
\text { apenas } 7 \% \text { em mádia nas } 4 \text { anos } \\
\text { anteriores }\end{array}$ \\
\hline Contatos Imediatos do Terceiro Grau & $\begin{array}{l}\text { Devils Towrec, Wyoming. Estados } \\
\text { Unidos }\end{array}$ & $\begin{array}{l}75 \% \text { de aumento em } 1975,20 \% \text { dos } \\
\text { visitartes ainda haje vern por causa } \\
\text { do filme }\end{array}$ \\
\hline Thelma e Lauise & $\begin{array}{l}\text { Arches Natianal Monument em Moab, } \\
\text { Utah, EUA. }\end{array}$ & $19.1 \%$ de aumenta em 1991 \\
\hline Campa dos Sonhos & lowa, Estados Unidos & $\begin{array}{l}35.000 \text { visitantes em } 1991 \text {. } \\
\text { crescimento estável anualmente }\end{array}$ \\
\hline Seriado Dallas & $\begin{array}{l}\text { Southfork Panch, Dallas, Estados } \\
\text { Unidos }\end{array}$ & 500 mil visitantes ao ano \\
\hline O Senhor dos Anéis & Nava Zeländia & $\begin{array}{l}10 \% \text { de aumento anual entre } 1998 \\
\text { e } 2003 \text { apenas do Heino Unido }\end{array}$ \\
\hline Flares de Aça & Louisiana, Estados Unidos & $\begin{array}{l}4 \mathrm{~B} \% \text { de aumento anual depois do } \\
\text { lançamento }\end{array}$ \\
\hline O Ûltima das Moicanos & $\begin{array}{l}\text { Chimney Hock Park, North Carnlina, } \\
\text { EUA }\end{array}$ & $\begin{array}{l}25 \% \text { de aumento anual depois do } \\
\text { lançamenta }\end{array}$ \\
\hline Adoráveis Mulheres & $\begin{array}{l}\text { Orchard House, Concord, } \\
\text { Massachusetts, EUA }\end{array}$ & $\begin{array}{l}65 \% \text { de aumento anual depois do } \\
\text { lançamenta }\end{array}$ \\
\hline Trilogia Harry Patter & Várias locap̧ōes no Reina Unido & $\begin{array}{l}\text { Todas as locaçōes tiveram acréscimo } \\
\text { de } 50 \% \text { ou mais }\end{array}$ \\
\hline Missāo Impossível 2 & $\begin{array}{l}\text { Parquas Nacionais em Sidney. } \\
\text { Austrália }\end{array}$ & $200 \%$ de aumento em 2000 \\
\hline Nas Mantanhas dos Gorilas & Pluanda & $20 \%$ de aumentb em 1998 \\
\hline Crocodilo Dundee & Austrália & $\begin{array}{l}20.5 \% \text { de aumento de visitantes } \\
\text { norte-amaricanos entre } 1981 \text { e } 1988\end{array}$ \\
\hline A Praia & Tailandia & $\begin{array}{l}22 \% \text { de aumento no mercado jovem } \\
\text { em } 2000\end{array}$ \\
\hline To the Manor Born [*] & $\begin{array}{l}\text { Cricket St Thomas, Leisure Park. } \\
\text { Inglaterra }\end{array}$ & $37 \%$ de aumentb entre 1978 a 1980 \\
\hline Middlemarch $\left({ }^{*}\right)$ & Stamf ord, Lincolnshire, Inglaterra & $27 \%$ de aumentn em 1994 \\
\hline Quatro Casamentos e Um Funeral & Crown Hotel, Amersham, Inglaterra & Lotado por pela menas 3 anas \\
\hline Sua Majestade Mirs. Brown & $\begin{array}{l}\text { Osborne House, Uha de Wight, Reino } \\
\text { Unido }\end{array}$ & $25 \%$ de aumento \\
\hline Um Lugar Chamada Natting Hill & Kenwoud Hause, Inglaterra & $10 \%$ de aumento em 1 mês \\
\hline Em Busca do Saldado Ayan & Normandia, França & $\begin{array}{l}40 \% \text { de aumento de turistas } \\
\text { norte-amaricanos }\end{array}$ \\
\hline Razāo e Sensibilidade & Saltram House, Inglaterra & $39 \%$ de asmento \\
\hline Orgulho e Precanceito & Lyme Park em Cheshire, Inglaterra & $150 \%$ de aumento de visitantes \\
\hline Trúia & Canakkala, Turquia & $73 \%$ de aumento de turismo \\
\hline O Capitāo Corelli & Cefalania, Grécia & $50 \%$ da aumento em 3 anas \\
\hline
\end{tabular}

Fonte: Brasil, (2007, p. 11).

Nota-se a apresentação de resultados positivos em cada locação citada, e que o aumento de turistas foi impactante com porcentagens elevadíssimas anualmente. Essa aliança entre o turismo e o cinema proporciona a divulgação de uma localidade até mesmo inexistente do cenário mundial. A interferência desses filmes no desenvolvimento turístico dessas cidades 
foi gigantesca, como se vê na tabela acima, em Wallace Monumente na Escócia com o filme Coração Valente, houve um aumento de mais de 300\% de visitantes após o lançamento do longa metragem. Não foi possível encontrar a metodologia usada para a definição dessa tabela, e nessa própria perspectiva, o impacto do filme diante dos visitados, como também, se havia outras ações ou eventos que puderam interferir na finalização do resultado da mesma.

Possivelmente, a tendência é que o turismo cinematográfico possa movimentar e agilizar uma série de investimentos estruturais em uma locação e em seu entorno devido à demanda ou fluxo de visitantes que serão envolvidos nos âmbitos social, cultural, ecológico, ambiental, territorial, econômico, etc.

O turismo cinematográfico abarca a influência de filmes, programas e séries de TV, e publicidade nas decisões de turistas ao escolherem os destinos para visitar. A representação nas telas das cidades e regiões tem um impacto econômico significativo no turismo e no fortalecimento da promoção cultural das regiões. Apesar de não existirem muitas estatísticas sobre o tema no Brasil, estima-se que o turismo cinematográfico global movimente cerca de 40 milhões de turistas a cada ano. O turismo induzido pelo cinema e pela TV já é considerado uma fonte significativa de benefícios para regiões específicas, e vários países têm orientado toda sua estratégia oficial de promoção turística precisamente em função da difusão das locações onde foram rodados filmes e séries de TV (Solot, 2015, p. 01).

A seguir, são mostrados na figura 02 , os possíveis benefícios que a união do turismo com o cinema pode oferecer para uma localidade:

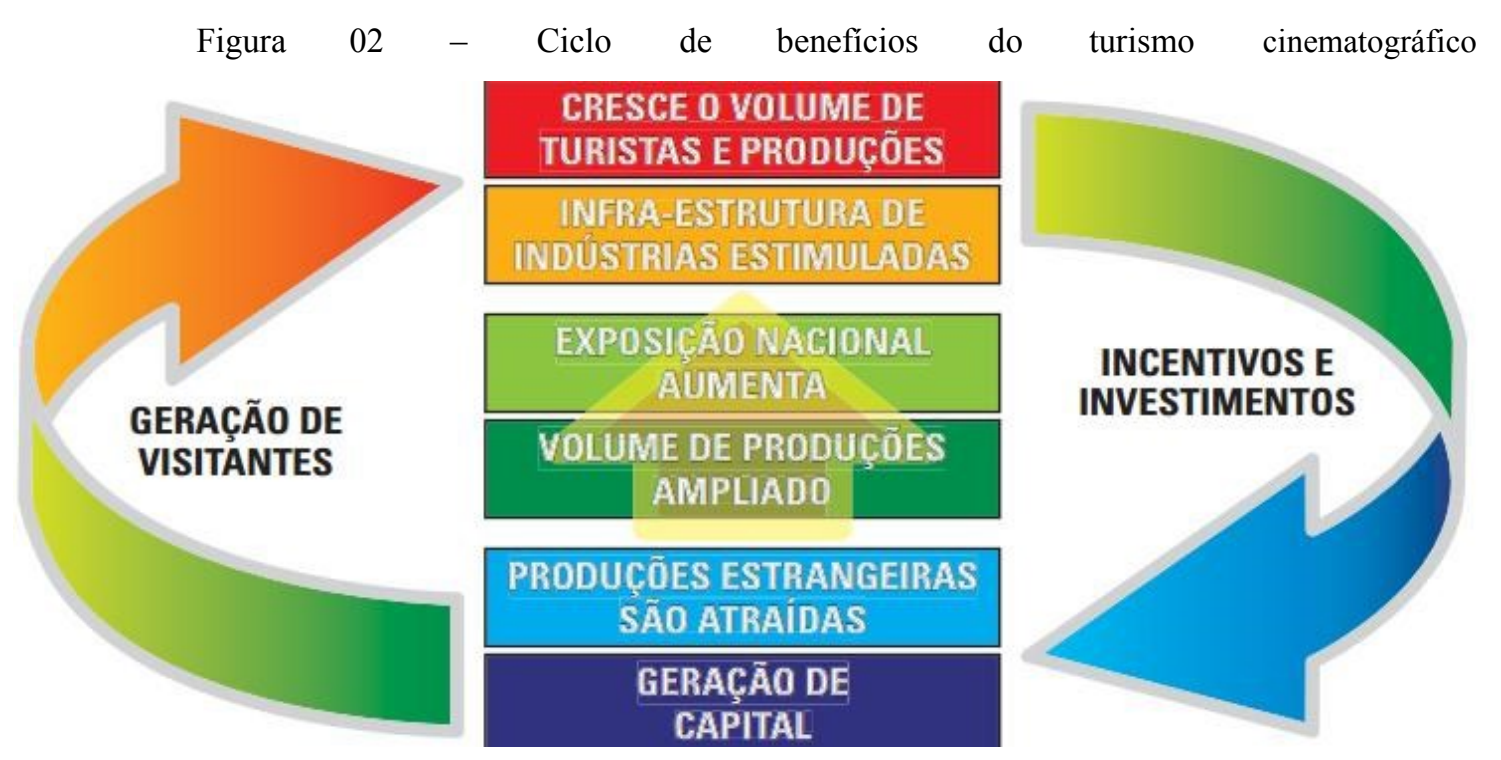

Fonte: Brasil, (2007, p. 12)

Inegavelmente, o turismo cinematográfico possibilita impactos marcantes, como visto 
na figura acima, apresentando possíveis benefícios para uma localidade, como a demanda de turistas. Esse segmento do turismo é atualmente uma das grandes estratégias do turismo mundial, consagrando locações quase desaparecidas do cenário nacional e internacional como a Nova Zelândia onde foi feito o filme da trilogia O Senhor dos Anéis, vencedor de quatro Oscar, "A Nova Zelândia gaba-se, com razão, do aumento em quase 300\% no número de visitantes após o lançamento da trilogia O Senhor dos Anéis (Brasil, 2007, p. 04)", como é mostrado na figura 03 a seguir:

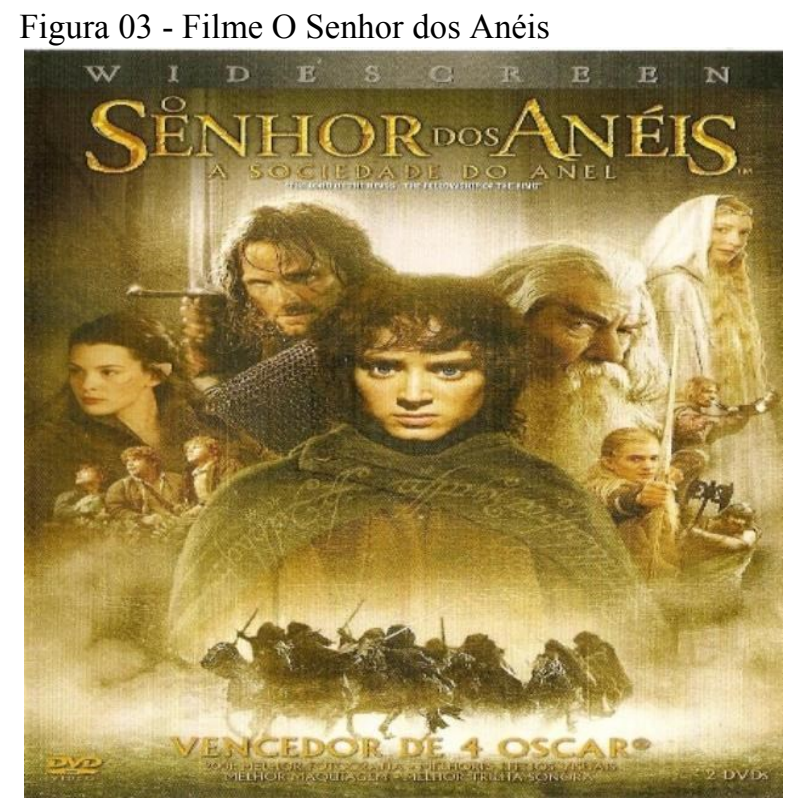

Fonte: www.google.com

Quando assisti O Senhor dos Anéis pela primeira vez fiquei me perguntando se aquelas paisagens também eram efeitos especiais, uma tela de fundo verde ou se realmente existiam. Quando as agências de turismos de lá começaram a receber muitos, mas muitos estrangeiros interessados em conhecer o Condado, Mordor ou Minas Tirith, uma luz se acendeu e eles começaram a encaixar as peças: o cinema é sim uma fonte de turismo. 9\% do PIB da Nova Zelândia é derivado do Turismo, claro, nem tudo é cinema por lá. [...], desde 2012 vem lançando belíssimas ações de marketing para promover o país, afinal, estamos falando aqui de filmes que arrecadam na casa dos bilhões. A Nova Zelândia é o lugar ideal para fãs de cinema, paisagens naturais, esportes radicais e principalmente, qualidade de vida (Matos, 2014, pp. 0102).

Observa-se que a Nova Zelândia explorou muito bem seus cenários turísticos através da parceria entre o turismo e o cinema, houve impactos positivos no país como o crescimento de turistas. A região se caracterizou como a alma da trilogia cinematográfica para o mundo, 
beneficiando grandes investimentos no país, para Hayata e Madril (2009, p. 54), “[...] quando uma produção elege um local para ser a base de filmagem, seja uma grande cidade ou uma região natural, traz um grande fluxo de investimentos imediatos e tende a causar no futuro um fluxo de turistas proporcional ao esforço de marketing gasto nessa direção", e não será diferente sendo implementado em Belém do Pará ou em qualquer locação, mas é preciso fazer muito bem o dever de casa como investimentos estruturais e uma intersetorialidade entre todos os atores envolvidos, principalmente do Governo Estadual e Municipal.

\subsection{ANÁLISE DOS RESULTADOS DA PESQUISA DE CAMPO EM BELÉM}

A Estação das Docas, como verifica-se nas figuras 04, 05 e 06. É um dos pontos turísticos mais visitados da capital paraense.

Figuras 04, 05 e 06 - Estação das Docas: da Esquerda para direita: Manhã, fim de tarde e noite.

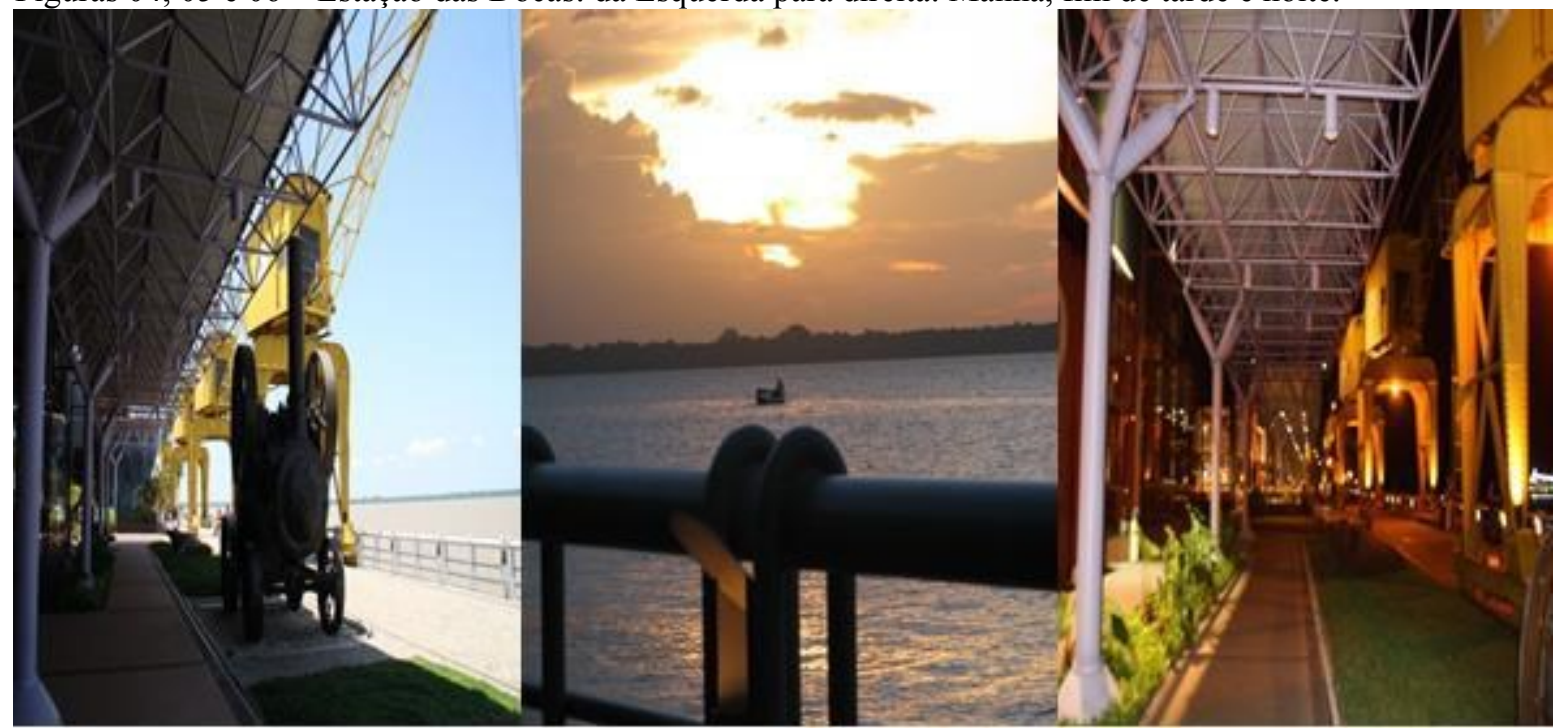

Fotos: Autor (2015)

Observou-se que no cotidiano da capital paraense A Estação das Docas, a partir do ano 2000 quando foi inaugurada, tem uma frequência altíssima de turistas e frequentadores diariamente, por isso é destaque entre os pontos turísticos de Belém do Pará com uma paisagem diferenciada. Localiza-se na Avenida Boulevard Castilhos França no bairro da Campina, com uma arquitetura restaurada, reconstruída e revitalizada do antigo porto pelo Governo do Estado do Pará com aproximadamente 500 metros de orla. Abrange um espaço turístico e cultural que passou a funcionar como mais uma opção de lazer, turismo, eventos, etc., possibilitando diversas atratividades e entretenimentos como o pôr-do-sol e a chegada da 
noite à margem da Baía do Guajará, que sem dúvida, é uma das grandes atrações para os turistas e para a população local.

A orla à margem da Baía do Guajará, que perpassa por todos os espaços da Estação das Docas, chamada Caminho do Sol, permite que os visitantes deste espaço tenham vista da baía, além de neste espaço também ocorrerem algumas manifestações culturais, como rodas de carimbo e apresentações de bois bumbás (Castro\& Figueiredo, 2013, p. 194).

Com certeza, essas singularidades que há na Estação das Docas faz a diferença, pois permite que visitantes locais, nacionais e internacionais possam desfrutar desse espaço turístico, de lazer e cultural. Como também, contemplar o pôr-do-sol à margem da Baía do Guajará, citado acima pelos autores. Existe uma frequência mínima, de aproximadamente, três milhões de pessoas por ano que visitam esse espaço turístico.

Conversando com alguns turistas, frequentadores e funcionários do espaço turístico, entre os dias 12 a 17 de novembro de 2015, em um total de 17 pessoas, a maioria do público feminino, solteiras, estudantes do ensino superior, com idade média de 23 anos, perguntou-se: Como poderia A Estação das Docas ser mais aproveitada para a realização de uma produção cinematográfica?

Cerca de $75 \%$ dos entrevistados relataram a importância das particularidades culturais, gastronômicas, naturais e arquitetônicas que o espaço oferece. Cerca de $5 \%$ disseram que o espaço pode ser aproveitado para relatar a história do porto e sua ajuda social e econômica para Belém. Cerca de 20\% expuseram que o lugar pode ser inserido para descrever o que era antes e para o que ele serve atualmente, ou seja, o sentido e a contribuição turística do local para o turismo na região, nessa perspectiva é mostrado no gráfico a seguir:

Gráfico: Aproveitamento da Estação das Docas

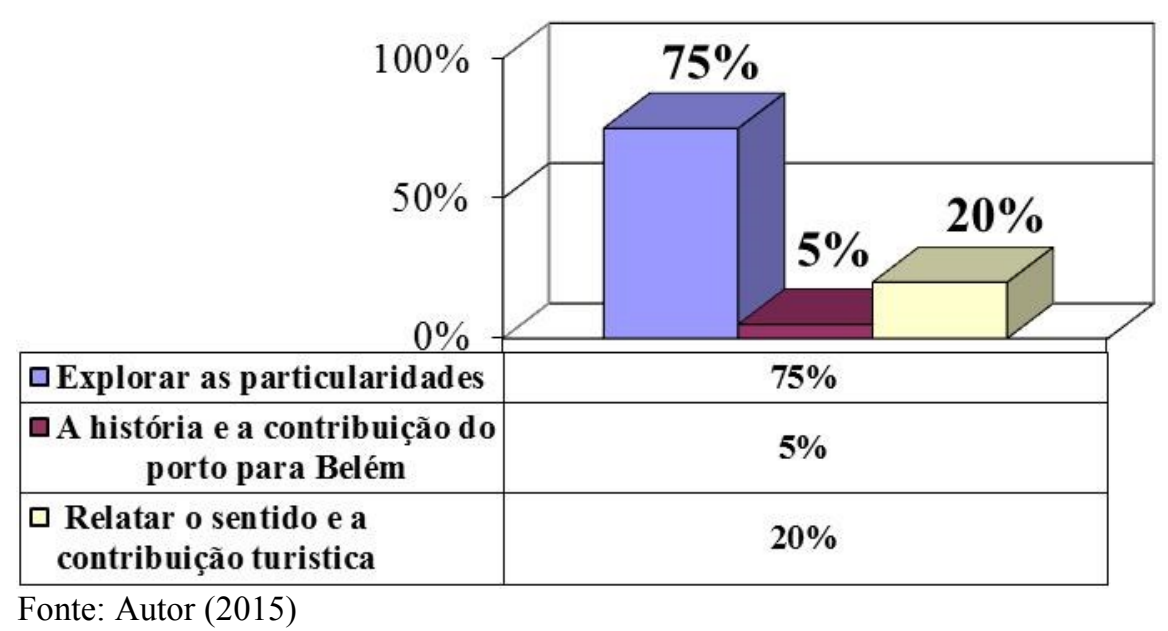


Analisa-se com base nos dados, essa possibilidade de implementação do turismo cinematográfico sendo mais uma alternativa de divulgação da localidade, A Estação das Docas será um forte atrativo para servir de paisagem, protagonista e/ou pano de fundo de um filme, de um documentário ou de uma novela, como já aconteceu na novela da Rede Globo Amor Eterno Amor em 2012, onde foram filmadas algumas cenas importantes com os personagens principais e tendo como pano de fundo a orla fluvial à margem da Baía do Guajará, além das ilhas do outro lado da baía serviram de paisagem.

Também observando os mesmos dados, poderia ser muito interessante relatar a história do porto e seu singular valor social e econômico para Belém com o trabalho de importação e exportação desde a época áurea da borracha até os dias atuais. Nesses mesmos dados, descrever a importância da Estação das Docas para o turismo no Estado desde a sua inauguração até hoje, e sua ímpar contribuição para o turismo e para a cadeia produtiva local.

O turismo cinematográfico permite essa possibilidade de interação para promoção, divulgação e marketing da imagem de uma cidade, além do fomento da economia na região com a chegada de visitantes, e possivelmente, a probabilidade de novos negócios. Contudo, fixado e sendo constante, poderá ser um forte aliado na difusão da localidade, pois normalmente há uma deficiência no setor de comunicação no processo de explorar a imagem da locação para outros estados e países. As autoridades públicas e privadas e suas equipes poderiam torna-se parceiros para criar alternativas para divulgar o que a cidade de Belém tem de melhor como Estação das Docas e outros pontos turísticos (Theatro da Paz, Ver-o-peso, Portal da Amazônia, Mangal das Garças, etc.), usando todos os meios de comunicação em massa (cinema, televisão e a internet).

É importante salientar que as ações para implementar o turismo cinematográfico destacarão as imagens dos principais pontos turísticos. A chegada de novos visitantes na capital motivará o turismo receptivo e fortalecerá a rede hoteleira e toda a cadeia produtiva na metrópole paraense e em seu entorno em curto, médio e longo prazo.

[...] muitos novos negócios podem ser desenvolvidos a partir da criatividade da região em explorar subprodutos gerados a partir da filmagem na região, como a produção de pacotes turísticos e mapas de locações, criação de souvenirs, entre outros (Brasil, 2007, p. 07).

Essa aliança entre o turismo e cinema em Belém ou em qualquer localidade proporciona oportunidades tanto no presente quanto para o futuro. Possibilita muitas 
atividades durante e depois das filmagens, segundo o MTur, "[...] podendo levar até três meses para ser produzido. Isso sem falar do turismo que é feito por artistas e outros profissionais envolvidos nas produções, o que é muito comum” (Brasil, 2007, p. 06), além de valorizar o que se tem de melhor na cidade, e com certeza, a partir dessa ideia motivará a visita de novos turistas promovendo-a como destino turístico.

\subsection{BRASÍLIA: REFERÊNCIA EM TURISMO CINEMATOGRÁFICO NO BRASIL, FILM COMMISSION E A RELAÇÃO COM O TURISMO CINEMATOGRÁFICO.}

Desde 2008, Brasília tornou-se referência em turismo cinematográfico no Brasil, um segmento que se caracteriza por ser moderno, inovador e criativo. Para Silva, Ligocki, Paludetto e Solot, (2010, p. 09), "[...] a escolha da capital federal como destino indutor do turismo cinematográfico levou em consideração a vocação natural de Brasília neste nicho de negócios, por suas locações diferenciadas que podem servir de cenário para filmes [...]". A cidade de Brasília foi construída na era do atuante presidente da república Juscelino Kubitschek a partir da década de 50, em um projeto ousado do urbanista Lúcio Costa e do gênio criador arquiteto Oscar Niemayer (Brasil, 2010). A capital federal é apontada como padrão arquitetônico diferenciado, e por isso e muito mais, produções audiovisuais nacionais e internacionais, exploraram seus cenários urbanos (Brasil, 2010), inserindo-a como protagonista de vários filmes, documentários, publicidades, entre outros.

Suas características turísticas e arquitetônicas têm criado uma profunda interação entre o turismo e o cinema. Segundo os autores, “[...] já foram realizados mais de 200 filmes, sendo que no mínimo, mais de 50 filmes retrataram a cidade como personagem ou figurante do tema" (Brasil, 2010, p. 18; Silva, et al., 2010, p. 09). Brasília tem sido alvo das curiosidades dos visitantes desde sua fundação, de acordo com Albernaz (2009, p. 03), “[...] Brasília sempre esteve ligada ao audiovisual por ser uma cidade contemporânea, foi filmada desde a sua construção em outubro de 1956".

Com o apoio de uma Film Commission, que tem a finalidade comercial de divulgar as imagens de uma locação através do audiovisual, fez a diferença quando foi criada na localidade, e começou a espalhar e promover a imagem da capital federal.

Criada em 1997 a Brasília Film Commission.

Finalidade: promover e divulgar Brasília como local atraente para realização de produções audiovisuais pelas excelentes condições naturais da cidade e entorno, e pelos mecanismos facilitadores da produção. 


\begin{abstract}
A Comissão de Filmagem agiliza o apoio institucional prestando serviços gratuitos de coordenação ou mediação com órgãos responsáveis por segurança, saúde, transporte, eletricidade, telecomunicações, licenças de filmagens, e dá consultoria e ajuda sobre locações, legislação de incentivo, materiais técnicos e mão-de-obra especializada disponíveis na região (Silva, et al., 2010. p. 20).
\end{abstract}

Verifica-se que a Brasília Film Commission a partir do momento que foi criada ajudou sensivelmente a promover cada vez mais a capital federal como destino com foco para produções cinematográficas, valorizando-a turisticamente e entrando definitivamente no mercado audiovisual.

Criar uma film commission atuante é estimular, fortalecer e divulgar a imagem de qualquer cidade promovendo-a como destino turístico.

Essas entidades são responsáveis por mediar a relação entre os produtores e as locações disponíveis na região, através da oferta de serviços de filmagem, equipamentos, mão-de-obra e outros serviços relacionados à produção, no sentido de atrair novas produções. Por meio dessa articulação, a film commission consegue gerar produção audiovisual para a localidade e, assim, na medida em que essa produção for transmitida e retransmitida nos mais diversos canais, aumenta-se a possibilidade de geração de fluxo turístico na localidade. Não se sabe ao certo quantas film commissions o país possui. Há uma especulação de que este número gire em torno de 15 entidades. [...]. O cenário ideal seria uma entidade para cada localidade turística brasileira, já que as representações locais sabem trabalhar melhor com os recursos disponíveis em cada uma dessas localidades e oferecer um produto melhor estruturado para o mercado (Duarte, 2015, p. 02).

Considera-se que a criação de uma Film Commission é fundamental importância para agilizar e articular o processo de divulgação da imagem da locação com a possibilidade de facilitar o trabalho dos produtores audiovisuais, direcionando e acelerando informações sobre uma localidade e promovendo o potencial turístico a nível nacional e internacional.

O turismo cinematográfico diferencia-se do turismo tradicional, que teoricamente é de viagens e lazer ou variando em suas complexidades. A capital federal serve de exemplo para outras capitais brasileiras, e principalmente para Belém do Pará que possui potenciais turísticos, singularidades e cenários (Theatro da Paz, Ver-o-peso, Mangal das Garças, Portal da Amazônia, etc.) que podem servir de pano de fundo para uma obra cinematográfica, mas ainda não possui um direcionamento nesse segmento do turismo. De acordo com o MTur (2010):

O Brasil tem grande potencial para se destacar como locação de diversas produções cinematográficas e canalizar os benefícios em favor de um aumento da demanda turística, a orientação do MTur para que isso ocorra é investir em ações como: 
Criação de um pacote atrativo, unificando incentivos fiscais às virtudes nacionais.

- Apoio e chancela governamental à atuação da rede nacional de film commissions.

mivulgação da cultura e imagens típicas da geografia aos olhos do grande público mundial, agregando valor ao audiovisual em conjunto com o turismo e a economia local.

m Incentivo à modernização da infraestrutura e potencialização do talento criativo nacional com formação e qualificação de mão-de-obra técnica.

Essas e outras ações visam tornar possível o desenvolvimento dos potenciais nacionais e superar os desafios impostos pela modernidade e a globalização, inserindo o turismo cinematográfico e setores complementares na economia criativa brasileira, usufruindo de seus inúmeros benefícios (Brasil, 2010, p. 07).

Verifica-se para que Belém do Pará possa se tornar um destino de referência nesse nicho cinematográfico, é preciso existir projetos direcionados, apoio financeiro e fiscal com empresas públicas e privadas para produções de curtas, médias e longas metragens, buscando sempre os apoios do Governo Municipal, Estadual e Federal de acordo com as Leis culturais de incentivo a arte, órgãos oficiais de turismo e da sociedade local.

Portanto, para que o trabalho seja intersetorial e faça desse segmento mais uma alternativa para o desenvolvimento e divulgação do turismo na capital paraense, é imprescindível haver estratégias, criatividade, planejamento, organização, integração, apoio político e público. O turismo cinematográfico tem crescido mundialmente, principalmente na divulgação da imagem de uma locação, no fortalecimento da cadeia produtiva e na receptividade turística de uma cidade e seu entorno.

\section{CONCLUSÃO}

A pesquisa não finaliza por aqui, visto que ainda é inicial. As investigações sobre a implementação do turismo cinematográfico possuem resultados parciais, que ao logo do tempo, surgirão novas e determinadas possibilidades e mais discussões serão levantadas em diferentes períodos. Cientificamente ainda é pouco estudado em relação a outras segmentações do turismo, pois o desenvolvimento ainda é raro para ser realizada uma profunda e completa avaliação para os destinos turísticos.

Observou-se que a relação do turismo e do cinema pode proporcionar alternativas para o crescimento da demanda turística no Brasil e no mundo, pois é inovador, criativo e moderno. Essa aliança possui uma responsabilidade socioeconômica, uma vez que é possível 
aproveitar toda a temática para trabalhar dentro das potencialidades turísticas, naturais, patrimoniais, gastronômicas, artísticas e culturais existente em uma localidade e em seu entorno. O turismo cinematográfico, mesmo timidamente, tem surgido como uma opção mercadológica turística nacional e internacional.

Verifica-se que uma das possibilidades para implantação e visibilidade, poderia ser inicialmente a criação de uma film commission atuante, pois tem o objetivo mercadológico de divulgar a imagem de uma locação. Na capital paraense ainda não tem nenhuma iniciativa com esse foco, nenhum plano ou estratégias para começar o desenvolvimento desse segmento do turismo, mesmo possuindo cenários turísticos como $\mathrm{O}$ Theatro da Paz, A Estação das Docas, O Complexo Feliz Lusitânia, O Parque Mangal das Garças, O Ver-o-Peso, etc., que podem servir ainda mais, como já serviram, de personagem, pano de fundo e/ou protagonista para filmes, novelas, documentários, publicidades, entre outros, principalmente para retratar sobre o cotidiano amazônico. Já houve produções na região, mas não no sentido de divulgação e/ou promoção turística, focados no direcionamento da capital paraense como destino ou atrativo turístico.

Ressalta-se que o fato do turismo cinematográfico proporcionar benefícios antes mesmo da vinda de turistas específicos ou não, possibilita a utilização dos serviços básicos e turísticos por parte da equipe de produção que estiver trabalhando na localidade, além de inserir a comunidade local em virtude da necessidade da produção cinematográfica, que sempre precisa do apoio da mão-de-obra regional para algum trabalho específico ou não.

Portanto, é possível implementar em Belém do Pará ou em qualquer região o turismo cinematográfico, desde que seja planejado, organizado e aproveitado todas as singularidades regionais. O tema está aberto para inúmeras reflexões, discussões e novos estudos. É necessário também uma intersetorialidade entre todos os atores envolvidos (Governo Estadual, Municipal, agentes do turismo, realizadores audiovisuais, sociedade, etc.) para o desenvolvimento do assunto na localidade.

Por fim, propõem-se algumas questões para serem refletidos e debatidos para fortalecer e fomentar a implementação do turismo cinematográfico:

Como buscar apoio e incentivo público, privado, do empreendedorismo, da comunidade e de parceiros a fins para implementar o turismo cinematográfico e criar uma film commission? 
Identificar uma identidade turística mais dinamizada para valorização das potencialidades e atratividades que Belém do Pará possui como estratégia para fortalecer ainda mais o turismo religioso, o turismo cultural, o turismo gastronômico, etc., criando um leque para a união do turismo com o cinema.

- Investir na contratação de profissionais qualificados e com formação acadêmica para a criação de planos e estratégias para dinamizar a promoção, a divulgação e o marketing através dos meios de comunicação em massa (cinema, televisão e internet).

Motivar a intersetorialidade entre todos os atores envolvidos (Secretaria de Turismo, Agentes e Agência de Viagens, Empresas de receptivo, etc.) e do cinema (Associação, Críticos de cinema, Realizadores, Produtores, etc.).

Incentivar o desenvolvimento do turismo para restaurar, revitalizar, preservar, proteger e conservar os cenários turísticos, históricos e culturais, pois eles podem servir de cenários ou pano de fundo para novas e inúmeras produções cinematográficas nacionais e internacionais.

\section{REFERÊNCIAS}

Almeida, D., Fumega, J.\& Alves, T. (2009). Cinema e turismo. Universidade de Lisboa. Lisboa. Lisboa:Territur-CEG. Recuperado em 17 setembro, 2014, de http://genesis.home.sapo.pt/Doc/Art_8.pdf

Albernaz, P. C. (2009). Curta Brasília: a imagem da cidade no olhar do cinema e sua relação com o turismo. Dissertação de Mestrado, Universidade Federal de Brasília, Brasília, DF,

Brasil. Recuperado em 18 agosto, 2014, de http://www.cet.unb.br/attachments/1207_Curta\%20Bras\%C3\%ADlia.PDF

Azevedo, F. F., Figueiredo, S. L., Nóbrega, W. R. M. \& Maranhão, C. H. S. (2013). Turismo em Foco: globalização e políticas públicas. In F. F. Azevedo, S. L. Figueiredo, W. R. M. Nóbrega \& C. H. Maranhão (Orgs.). Turismo em Foco. (Vol. 1, Cap. 1, pp. 11-27). Belém, PA: NAEA

Barradas, M. (2013). Turismo cinematográfico impulsiona destinos. Publituris - Edição Digital-Portugal. Recuperado em 04 junho, 2016, de http://www.publituris.pt/2013/12/05/turismo-cinematografico-impulsiona-destinos/

Brasil. Ministério do Turismo \& Instituto Dharma. (2007) Cartilha do turismo cinematográfico brasileiro. Brasília: Ministério do Turismo. Recuperado em 23 junho, 2014, de

http://www.turismo.gov.br/sites/default/turismo/o_ministerio/publicacoes/downloads_publica coes/Cartilha_Cinema.pdf 
Brasil. Ministério do Turismo. (2007). Estudos de sinergia e desenvolvimento entre as indústrias do turismo \& audiovisual. Brasília: Ministério do Turismo. Recuperado em 30

junho, 2014, de http://www.turismo.gov.br/sites/default/turismo/o_ministerio/publicacoes/downloads_publica coes/Estudo_Completo_Cinema.pdfBrasil. Ministério do Turismo.

Brasil. (2008). Lei $n .1 \overline{1} .771$, de 17 de setembro de 2008: Dispõe sobre a Lei geral do turismo. Brasília. Recuperado em 23 agosto, 2014, de http://www.planalto.gov.br/ccivil_03/_ato2007-2010/2008/lei/111771.htm

Brasil. Câmara dos Deputados. (2010). Escrevendo a História: 50 anos de Brasília. Brasília. Recuperado em 22 agosto, 2014, de http:/www2.camara.leg.br/atividadelegislativa/plenario/discursos/escrevendohistoria/revista-50-anos-de-brasilia

Castro, C. A. T. \& Figueiredo, S. L. (2013). Turismo, políticas públicas e espaços públicos urbanos: a Estação das Docas em Belém, Pará. In F. F. Azevedo, S. L. Figueiredo, W. R. M. Nóbrega \& C. H. Maranhão (Orgs.). Turismo em Foco. (Vol. 1, Cap. 10, pp. 189-202). Belém, PA: NAEA

Didio, L. (2014). Como produzir monografias, dissertações, teses, livros e outros trabalhos. (152 p.). São Paulo: Atlas.

Duarte, R. (2015). Turismo cinematográfico - hã? Rio de Janeiro: Folha . Recuperado em 04 junho, 2016 de http://folharj.com.br/2015/08/28/turismo-cinematografico-ha/

Endres, A. V. (2015). Turismo e o desenvolvimento local: o capital social e as redes de políticas públicas em foco. In S. L. Figueiredo, F. F. Azevedo \& W. R. M. Nóbrega (Orgs.). Perspectivas contemporâneas de análise em turismo. (Vol. 1, Cap. 15, pp. 288-308). Belém, PA: NAEA.

Google.com. (2014). Foto da trilogia O Senhor dos Anéis. Recuperado em 08 de novembro, 2014, de https://www.google.com.br/search?gs_rn=24\&gs_ri=psyb\&pq=normas + da + abnt\&cp $=13 \& g s$ $\mathrm{id}=3 \mathrm{e} \& \mathrm{xhr}=\mathrm{t} \& \mathrm{q}=$ senhor $+\mathrm{do}+\mathrm{an} \% \mathrm{C} 3 \% \mathrm{~A} 9 \mathrm{is} \& \mathrm{bav}=$ on.2,or.r_qf.\&bvm=bv.50500085, d.eWU\& biw $=1024 \&$ bih $=679 \& u m=1 \& i e=U T F 8 \& h l=p t B R \& t b m=i s c h \&$ source $=0 g \& s a=N \& t a b=$ wi\&ei $=1 \mathrm{~d} 4 \mathrm{DUp}$ _BCITq8gSJIIGABA\&gws_rd $=$ ssl\#facrc $=$ _\&gws_rd=ssl\&imgrc $=$

Hayata, K. S. \& Madril, M. L. (2009). Turismo cinematográfico: um novo segmento para o desenvolvimento turístico. Monografia de Graduação. Faculdade Cásper Líbero, São Paulo, SP, Brasil. Recuperado em 17 setembro, 2014, de http://www.dadosefatos.turismo.gov.br/export/sites/default/dadosefatos/outros_estudos/downl oads_outrosestudos/Graduaxo_2_LUGAR.pdf

Instituto Casa Brasil de Cultura \& Instituto Dharma. (2010). Destino de Referência em Turismo Cinematográfico. Brasília. Recuperado em 18 setembro, 2014, de http://www.turismo.gov.br/sites/default/turismo/o_ministerio/publicacoes/downloads_publica coes/braslia.pdf 
Jung, C. F. (2003) Metodologia cientifica: ênfase em pesquisa tecnológica. (3a Ed.) Porto Alegre: UFRGS. Recuperado em 18 julho, 2014 de http://www.mecanica.ufrgs.br/promec/alunos/download/metodolo.pdf

Matos, L. (2014). Como a Nova Zelândia encontrou no cinema um incentivo para o turismo: Um belo país como excelentes números de desenvolvimento encontrou nas produções cinematográficas algo lucrativo. Recuperado em 04 junho, 2016, de http://www.amigosdoforum.com.br/como-nova-zelandia-encontrou-cinema-um-incetivo-parao-turismo/

Melo, A. C. V. (2009). Formulação de um modelo de observatório para o turismo cinematográfico em Brasília. Dissertação de Mestrado, Universidade de Brasília. Centro de Excelência em Turismo. Brasília, DF, Brasil. Recuperado em 17 agosto, 2014, de http://livros01.livrosgratis.com.br/cp107710.pdf

Rosa, A. P. (2014). Ecos virtuais no youtube. Significação: Revista de Cultura Audiovisual. 41(41), 236-257.

Rover, A. (2006). Metodologia científica: educação à distância. Joaçaba: UNOESC. Recuperado em 17 julho, 2014, de http://people.ufpr.br/ felipe/Apost_Metod_Cient-1.pdf

Schneider, A. C. (2012). Luz, câmera...turismo: as produções cinematográficas e as contribuições às cidades de Antônio Prado e Sapiranga. Monografia de Graduação. Universidade FEEVALE, Novo Hamburgo, RS, Brasil. Recuperado em 07 julho, 2014, de http://biblioteca.feevale.br/Monografia/MonografiaAnaCristina.pdf

Siena, O. (2007). Metodologia da pesquisa cientifica: elementos para elaboração de apresentação de trabalhos acadêmicos. Dissertação de Mestrado. Fundação Universidade Federal de Rondônia:UNIR, Porto Velho,RO, Brasil. Recuperado em 23 abril, 2015, de http://www.ppga.unir.br/downloads/104_manual_de_trabalho_academicorevisado_2011.pdf

Silva, A. C. C., Ligoki, M., Paludetto, R. \& Solot, S. (2010). Brasília cinematográfica: $2^{\circ}$ etapa de preparação do destino referência em turismo cinematográfico no Brasil. Brasília: Instituto Dharma. Recuperado em 25 setembro, 2014, de

http://www.turismo.gov.br/sites/default/turismo/programas_acoes/regionalizacao_turismo/do wnloads_regionalizacao/BrasiliaxCinematografica_2Brasil_2010.pdf

Solot, S. (2015). Uma imagem vale mais do que mil palavras. Cultura e mercado. Edição Digital. Recuperado em 04 junho, 2016, de http://www.culturaemercado.com.br/site/pontosde-vista/o-turismo-cinematografico-e-film-commissions/

Teixeira, E. (2003). As três metodologias: acadêmica, da ciência e da pesquisa.(2a Ed.). Petrópolis, RJ: Vozes. 